\title{
Relationship between wind speed and aerosol optical depth over remote ocean
}

\author{
H. Huang, G. E. Thomas, and R. G. Grainger \\ Atmospheric, Oceanic and Planetary Physics, University of Oxford, Oxford, OX1 3PU, UK \\ Received: 26 August 2009 - Published in Atmos. Chem. Phys. Discuss.: 18 November 2009 \\ Revised: 11 June 2010 - Accepted: 14 June 2010 - Published: 2 July 2010
}

\begin{abstract}
The effect of wind speed on aerosol optical depth (AOD) at $0.55 \mu \mathrm{m}$ over remote ocean regions is investigated. Remote ocean regions are defined by the combination of AOD from satellite observation and wind direction from ECMWF. According to our definition, many ocean regions cannot be taken as remote ocean regions due to long-range transportation of aerosol from continents. Highly correlated linear relationships are found in remote ocean regions with a wind speed range of $0-20 \mathrm{~ms}^{-1}$. The enhancement of AOD at high wind speed is explained as the increase of sea salt aerosol production.
\end{abstract}

\section{Introduction}

Marine aerosol constitutes one of the largest natural aerosol systems and plays an important role in the Earth's radiative budget. It comprises two distinct aerosol types: I) primary sea salt aerosol, and II) secondary sulphate aerosol. Many studies show that sea salt particles make a significant contribution to both submicron and supermicron maritime aerosol modes (Gras and Ayers, 1983; Hoppel et al., 1990; Fitzgerald, 1991; O'Dowd et al., 2001; Heintzenberg et al., 2003; Clarke et al., 2003). The major sources of sea salt aerosol are the bursting of bubbles formed primarily by breaking waves and mechanical disruption of wave crests by the wind (Exton et al., 1985; Andreas, 1998; O'Dowd and de Leeuw, 2007). Marine aerosol influences the radiative budget both directly and indirectly. These particles are the main contributor to light scattering in the cloud-free atmosphere in those regions with marine atmosphere. They also participate in cloud processes, serving as the dominant cloud condensation nuclei $(\mathrm{CCN})$ source over the remote ocean regions (Latham and

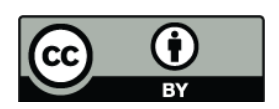

Correspondence to: $\mathrm{H}$. Huang

(huang@atm.ox.ac.uk)
Smith, 1990; Hegg, 1992; Ghan et al., 1998; Lohmann and Feichter, 2005; Satheesha and Moorthy, 2005). Therefore elucidating the background sea salt aerosol is important understanding the atmospheric radiative budget.

The effect of wind on aerosol over the oceans has been studied, but has mostly focused on the aerosol concentration and size distribution. Definite correlation has been found between surface wind speed and sea salt aerosol concentration (McDonald et al., 1982; O'Dowd and Smith, 1993; Nilsson et al., 2001). The influence of wind speed on marine AOD, $\tau$, in the atmosphere is a much more difficult problem (Platt and Patterson, 1986; Villevalde et al., 1994; Smirnov et al., 1995; Moorthy et al., 1997). The link between marine aerosol optical properties and wind speed is difficult to quantify because it can be masked by long-range transport from land based sources. Thus selecting oceanic regions far from continents, with no influence of long-range transport, is important for studying such a relationship.

Moorthy and Satheesh (2000) found an exponential increase in daily averaged AOD with wind speed at Minicoy in Arabian Sea. However, the region in that study is close to land so that it cannot be considered as a pristine marine environment.

Making use of AOD derived from MODIS and wind from NECP, Satheesh and Srinivasan (2006) examined the contribution of sea-salt to composite AOD over different regions of the Arabian Sea and found the contribution of sea salt varies with season and latitude. Based on long term (1988-2005) aerosol data from AVHRR, Mishchenko and Geogdzhayev (2007) found a downward trend of global aerosol loading which was consistent with ground based observation, though an increasing trend of AOD was also observed in the region of $40^{\circ} \mathrm{S}-60^{\circ} \mathrm{S}$. They indicated a positive correlation between the AOD and the wind speed, and also hinted that the correlation might not be very reliable due to the constant wind speed used in their aerosol retrieval algorithm. Mulcahy et al. (2008) obtained a power-law relationship at four different

Published by Copernicus Publications on behalf of the European Geosciences Union. 
wavelengths at Mace Head, located on the west coast of Ireland. This site is also cannot be considered representative of the remote ocean.

Based on one month of AOD data from the Sea-viewing Wide Field-of-view Sensor (SeaWiFS) and 10-m wind data from ECMWF, Glantz et al. (2009) found a power-law relationship between wind speed and AOD for the north Pacific. However in their study, a single surface reflectance value was used in the retrieval of AOD from SeaWiFS. The increased reflectance of the ocean due to increased surface roughness and white caps generated by enhanced wind could not be ruled out effectively.

Though many studies have been performed, there is still no consensus on the relationship between wind speed and observed AOD. Additionally, all of the previous studies were from different locations using different instruments and also in different time-periods. Hence a direct comparison between their results is difficult to make and it is hard to extrapolate the results to other areas. Also, some locations where the experiments were carried out are close to continents. In this paper, we first determine which oceanic areas can be taken as remote ocean, based on the wind directions and AOD, and then we investigate the relationship between AOD and wind speed over these regions, where the influence of continental aerosol can be considered minimal. The paper is organized as follows: In Sect. 2, we briefly explain the data and the instruments used. A quantitative method to distinguish remote oceanic regions from areas influenced by continental outflow is introduced in Sect. 3. Preliminary results and simple discussion are presented in Sect. 4. Concluding remarks are given in Sect. 6.

\section{Data}

The AOD used in the paper is at wavelength of $0.55 \mu \mathrm{m}$, daily for the whole year of 2004. It is retrieved from the Advanced Along-Track Scanning Radiometer (AATSR) by the Oxford-RAL Retrieval of Aerosol and Cloud (ORAC) algorithm as part of the ESA GlobAEROSOL project (Thomas et al., 2008). ESA GlobAEROSOL provides AOD at $0.55 \mu \mathrm{m}$ and $0.87 \mu \mathrm{m}$ on a $10 \times 10 \mathrm{~km}$ sinusoidal grid. These data have been regridded onto the $1^{\circ} \times 1^{\circ}$ degree dataset which is used in this paper. The AATSR is on board the European Space Agency's Envisat platform, which is in a sun-synchronous orbit with an overpass time of 10:30 a.m. local solar time. The instrument has seven channels centered at $0.55,0.67$, $0.87,1.6,3.7,11.0,12.0 \mu \mathrm{m}$. The distinguishing feature of AATSR is its dual-view system, which acquires two nearsimultaneous observations of the same area of the Earth's surface at a viewing angle of $55^{\circ}$ (forward view) and then approximately $90 \mathrm{~s}$ later at an angle close to vertical (nadir view). The two views, with different effective atmospheric paths, enable an accurate estimate to be made of the signal degradation due to atmospheric absorption and scatter- ing. The precision of AATSR at visible channels is better than $1 \%$, the brightness temperature in infrared channels are accurate up to $0.05 \mathrm{~K}$.

The ORAC is an optimal estimation (OE) scheme, the main principle is making use of Levenberg-Marquart iteration to find the best fit of modelled radiance based on the state of atmosphere and surface to the first four of AATSR's channels in both views. The algorithm uses a forward model, which is composed of sub-models of aerosol, gases and surface reflectance, to simulate the radiance at the top of atmosphere. ORAC retrieves AOD at $0.55 \mu \mathrm{m}$, aerosol effective radius and surface reflectance for each of the retrieval channels (under the constraint that the ratio of the surface reflectance in the forward and nadir views is fixed). The retrieval of effective radius is achieved by varying the mixing ratios of the different size modes (e.g. fine, accumulation and coarse) in externally mixed aerosol classes of fixed composition. For GlobAEROSOL, aerosol properties (refractive index, height profile and a priori size distribution) were taken from the Optical Properties of Aerosols and Clouds (OPAC) database (Hess and Schult, 1998). In the surface reflectance model, the Bidirectional Reflectance Distribution Function (BRDF) is used to describe the angular variation of the surface reflectance and the effects and variations of white caps, under light and sun glint are considered. More detail descriptions of the algorithm and forward model are given by Thomas et al. (2009a,b, 2010); Sayer et al. (2010).

As the aerosol retrieval is only possible in clear sky conditions, it is vital that pixels containing cloud are not included in the retrieval. The GlobAEROSOL AATSR product makes use of ESA's operational sea surface temperature cloud flag (Zavody et al., 2000). This uses a combination of thresholds on the thermal infrared channels, spatial coherence and ratios between different channels, and is believed to be quite reliable over the ocean.

Validation against Aerosol Robotic Network (AERONET) data shows the AATSR AOD product has a systematic positive bias of 0.056 (Portela et al., 2009). Although this result is for land based and coastal AERONET stations, and thus may not be directly applicable to the remote ocean, it does suggest that the GlobAEROSOL AATSR product suffers from a positive bias in its AOD values. However, since the bias appears to be relatively independent of AOD (Portela et al., 2009), it should have a limited impact on the observed AOD vs wind speed relationship. A possible reason for the possible bias in the AATSR AOD is contamination by residual cloud. Although the AATSR cloud mask is considered quite stringent, it is possible that thin cirrus, which is now believed to be very common (Baran, 2009), might not be removed. This could cause a small, consistent offset in the observed AOD.

The wind data used in this paper is $10 \mathrm{~m}$ wind from European Centre for Medium-Range Weather Forecasts (ECMWF), at the same temporal and spatial resolution as AOD data. The ECMWF wind is generated four times per day with a time interval of $6 \mathrm{~h}$. Wind fields have been 

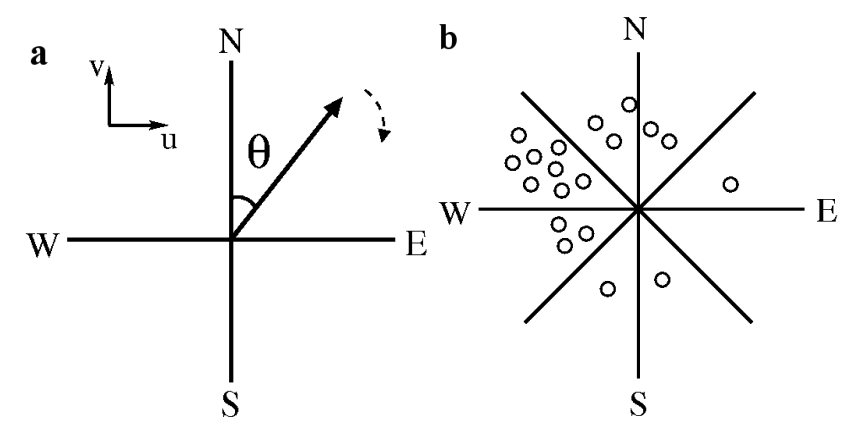

Fig. 1. (a). Definition of wind direction. (b). AOD (indicated by the circles) are categorized by wind direction.

interpolated to Envisat nominal overpass time by using the two time slots which are the nearest to the ENVISAT passover time. The life time of marine aerosol in the marine boundary layer (MBL) is in range of hours to days, so the error introduced by this coarse temporal resolution should be minimal.

Based on zonal $(u)$ and meridional $(v)$ wind components given by ECMWF, the wind speed $(s)$ is calculated using $s=$ $\sqrt{u^{2}+v^{2}}$ and wind direction is defined as shown in Fig. 1a.

\section{Method}

To get a clear understanding of the relationship between wind speed and AOD, the first step is to define the remote ocean regions. A heuristic argument can be made that, for truly remote oceanic regions, the only aerosol source is the ocean and thus the $\tau$ should not strongly depend on wind direction but only on wind speed and other parameters such as temperature and relative humidity. For each $1 \times 1^{\circ}$ grid cell in the global ocean, the wind direction ranges from $0^{\circ}$ to $359^{\circ}$ as shown in Fig. 1a. The wind directions are divided into 36 bins with an interval of $10^{\circ}$. The daily $\tau$ data are sorted into different bins according to the corresponding the daily wind directions. Fig. 1b illustrates a simple example with only eight bins chosen. We then calculate the average value $\left(\tau_{a v}\right)$ of $\tau$ in each bin and the standard deviation of $\tau_{a v}$ over all wind direction bins, $\sigma_{\tau_{a v}}$. The value of $\sigma_{\tau_{a v}}$ indicates the dependence of $\tau$ on wind direction. If $\sigma_{\tau_{a v}}$ is large, $\tau$ at the this point changes markedly as wind direction changes, indicating that a possible external source of aerosol exists. On the other hand, if the $\sigma_{\tau_{a v}}$ is small, $\tau$ shows no or weak dependence on wind direction, indicating that the corresponding area is a possible pristine oceanic candidate. This is shown stylistically in Fig. 2.

The histogram of $\sigma_{\tau_{a v}}$ for all global oceanic points is plotted in Fig. 3. The main peak in Fig. 3 is interpreted as the typical variability of $\tau$ as a function of direction. The large tail of high variability denotes aerosol being transported from

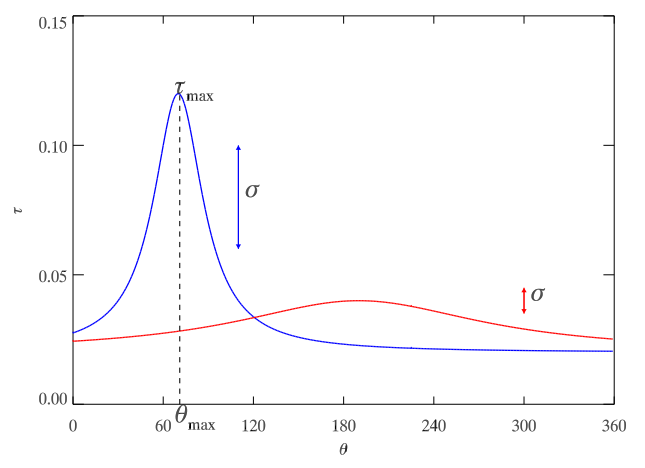

Fig. 2. For each $1^{\circ} \times 1^{\circ}$ point, $\tau$ is expressed as a function of wind direction. The blue curve represents the case where $\tau$ depends strongly on wind direction and so has a large $\sigma_{\tau}$. The red curve represents the case where $\tau$ does not depend on wind direction and so has a small $\sigma_{\tau}$. The $\tau_{\max }$ shows the wind direction in which the $\tau$ has the largest value.

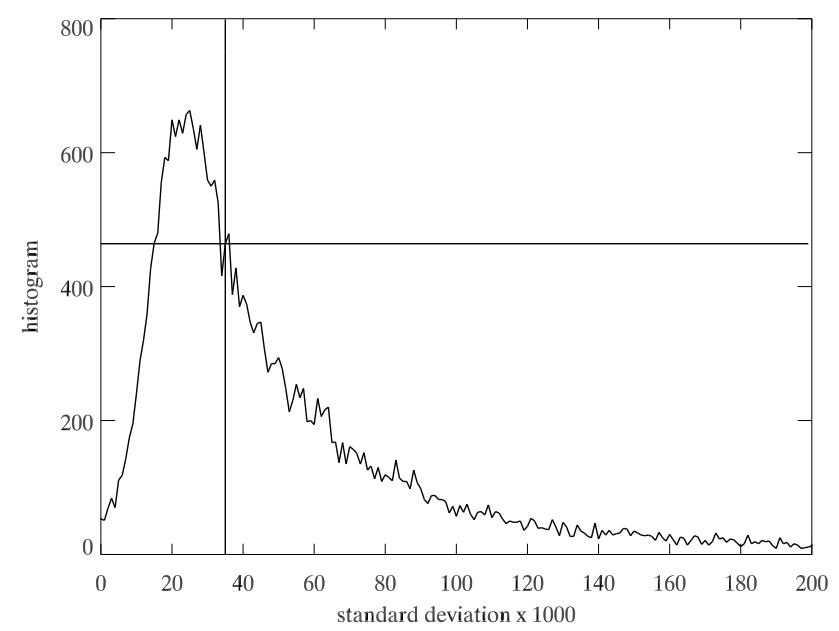

Fig. 3. Histogram of standard deviation $\sigma_{\tau_{a v}}$ for global ocean points, the cross point of black vertical and horizontal lines represents the chosen threshold

preferred directions. To differentiate locations with typical $\tau$, from those demonstrating a preferred direction we have used a threshold, $\sigma_{\tau_{a v}^{\mathrm{th}}}$, of about $2 / 3$ of the peak values (i.e. a value of 0.035 ). For any point, if $\sigma_{\tau_{a v}} \geq \sigma_{\tau_{a v}^{\mathrm{th}}}$, it implies there are possible external aerosol sources other than the ocean itself: we take these type of points to be candidates of nonremote ocean. For these points, the corresponding angle $\theta_{\max }$ is found where the $\tau_{a v}$ is maximum.

A global map of $\theta_{\max }$ is shown in Fig. 4. If the direction in indicated by $\theta_{\max }$ includes an obvious source of nonmaritime aerosol, then that location is taken to be non-remote ocean. It should be noted that some regions are dominated by winds from a single direction, or where the wind speed is strongly correlated with its direction. In such regions there 

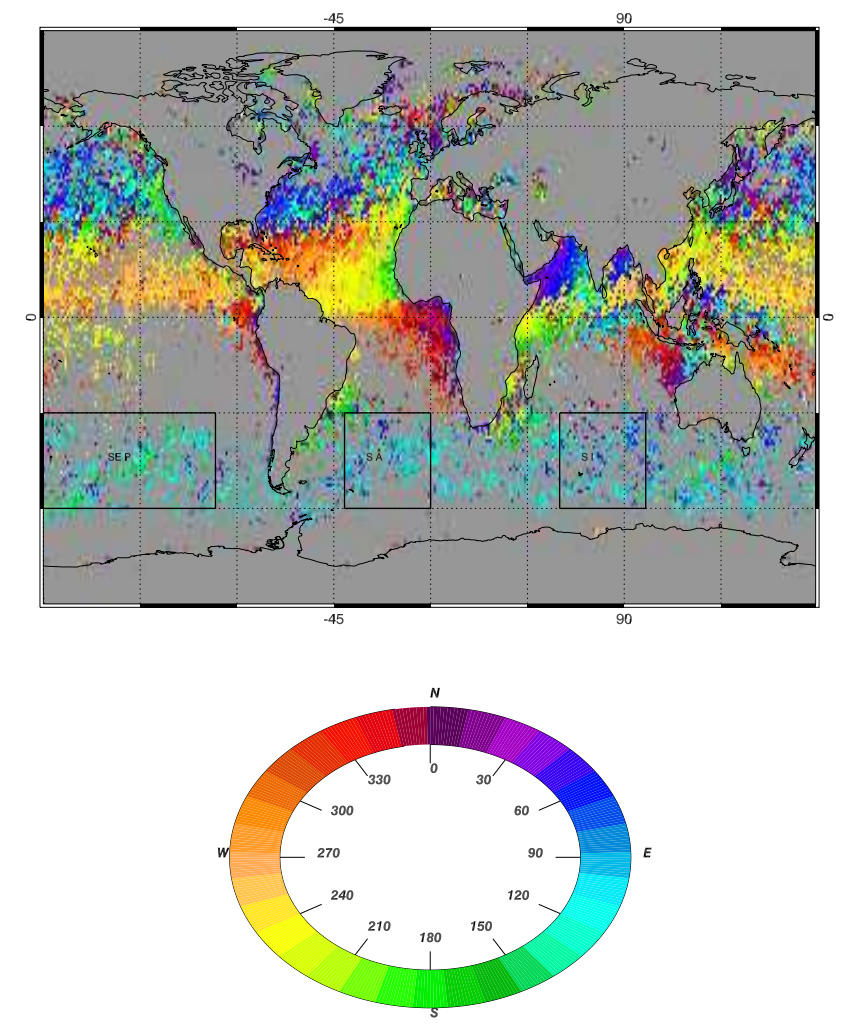

Fig. 4. Plot of wind direction $\theta_{\max }$ for the locations where $\sigma_{\tau}$ is greater than 0.035 . Rectangles indicate the three regions in which the dependance of AOD on wind speed has been examined.

is a strong relationship between $\tau$ and wind direction, even if there is no non-maritime aerosol source. Thus, if a region with a $\theta_{\max }$ value which doesn't indicate a non-maritime aerosol source, it can still be considered to meet the remoteocean criteria.

\section{Results}

Figure 4 indicates the source direction of transported aerosol for these points. This map roughly matches the large-scale flow field and storm tracks. For the mid-latitude ocean (30$60^{\circ} \mathrm{N}$ ) of the Northern Hemisphere, enhanced aerosol loading occurs with the wind direction is westerly, taking heavyindustry pollutants from East Asia and North America.

For the tropical and sub-tropical Atlantic regions, it is obvious that North Africa is the main source of aerosol for its surrounding areas. Over the sub-tropical and tropical Atlantic ocean, the $\theta_{\max }$ matches the direction of trade winds that transport dust from the Sahara. Over the year, AATSR observes the highest aerosol loading over the Persian Gulf, where wind comes from the south west. For the points located in the east central Pacific, $\tau$ is maximum with an east wind, indicating that the large values of $\tau$ over these points

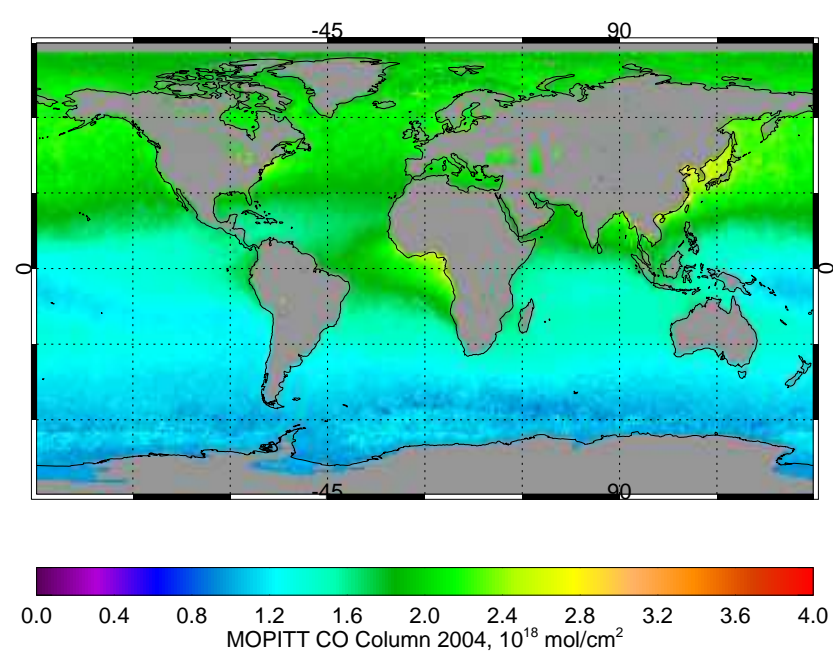

Fig. 5. Column CO distribution from MOPITT, 2004

probably relate to long-range transport aerosol from biomass burning in South America or dust from the Sahara. Over the west central Pacific, as well as the southern China sea, $\tau$ is largest when wind comes from a roughly northerly direction. This could be related to sand storms in northern China and Mongolia.

Over the southern oceans (between $30-60^{\circ} \mathrm{S}$ ), the largest $\tau$ occurs when wind directions in a range of $70^{\circ}$ to $140^{\circ}$ (see Fig. 1a), i.e. westerlies. Strong westerly winds are almost ubiquitous in the southern oceans, and it is this which causes this dependence of $\tau$ on $s$, rather than a particular source of transported aerosol. Indeed, as there are no large continents in this region, it can be thought of as a remote ocean region, with little influence from continents.

From Fig. 4, many regions, especially in the Northern Hemisphere, cannot be regarded as pure remote oceans. This interpretation is supported by the carbon monoxide (CO) distribution map from Measurements Of Pollution In The Troposphere (MOPITT), shown in Fig. 5. The two main sources for $\mathrm{CO}$ are industrial pollution and biomass burning (Sanderson, 2002; Singer, 1975). Although CO has a longer life time than aerosol, and thus cannot be taken as a proxy for aerosol, its distribution can provide a "worst case" indication of the regions which could be subject to long range aerosol transport. The high $\mathrm{CO}$ in the Northern Hemisphere indicates that those regions may be influenced by long-range transportation from land, while the regions between $30-60^{\circ} \mathrm{S}$ have relatively low CO concentrations. Experiments in regions showing evidence of influence of transport from continental sources aimed at measuring aerosol properties over remote ocean could lead to unreliable results.

Based on this analysis, we choose remote ocean points over three regions, shown as black frames in Fig. 4. Since they suffer less influence from land, the loading aerosol 


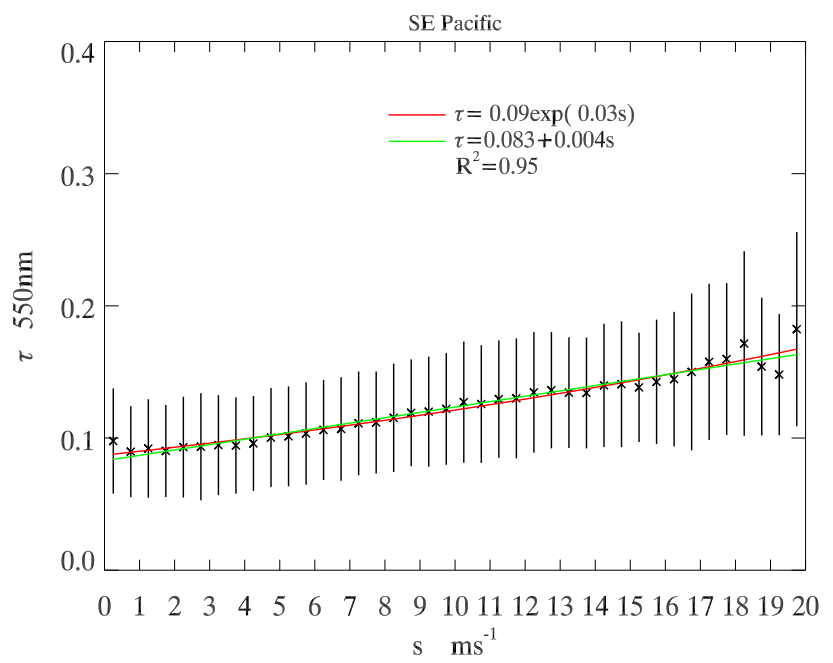

Fig. 6. Relationship between wind speed $s$ and AOD $\tau$ over the South East Pacific. $R^{2}$ in the plot is the linear correlation coefficient between wind and $\tau$.

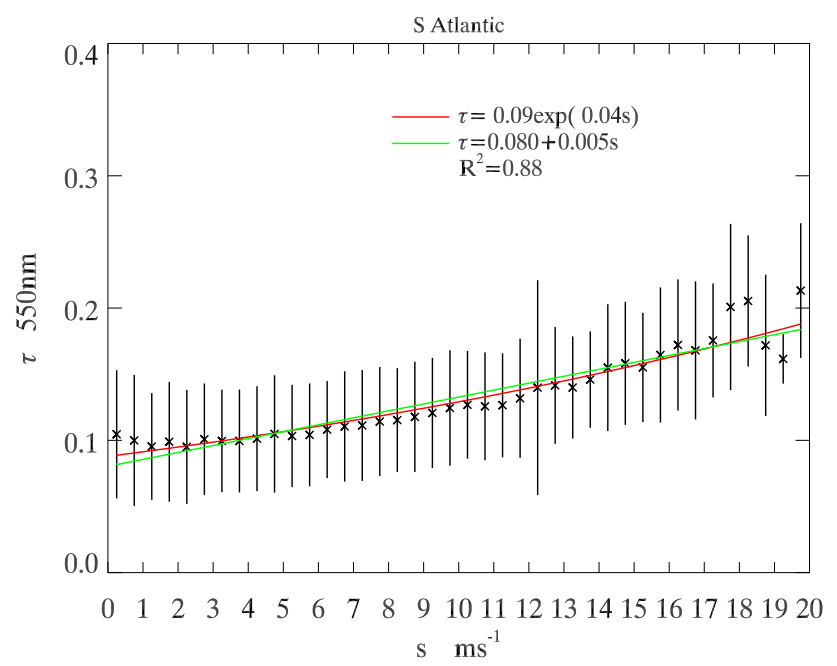

Fig. 7. Relationship between wind speed $s$ and AOD $\tau$ over the South Atlantic Ocean.

for these regions are free from contamination by long-range transported aerosol and it is possible to establish a link between marine $\tau$ and wind speed. The relationship between wind speed and $\tau$ for these regions is plotted in Figs. 6 to 8 . The error bar in the plots is the standard deviation of AOD in each wind interval $\left(0.5 \mathrm{~ms}^{-1}\right)$. All plots show a similar relationship between wind speed and AOD, which is largely linear up to $s=20 \mathrm{~ms}^{-1}$. The AOD is observed to increase by around 0.1 over a wind speed range of 4 to $20 \mathrm{~ms}^{-1}$. We interpret this significant increase to the enhanced contribution of sea salt particles. Importantly, there is no indication that an exponential function is a better fit to the measurements

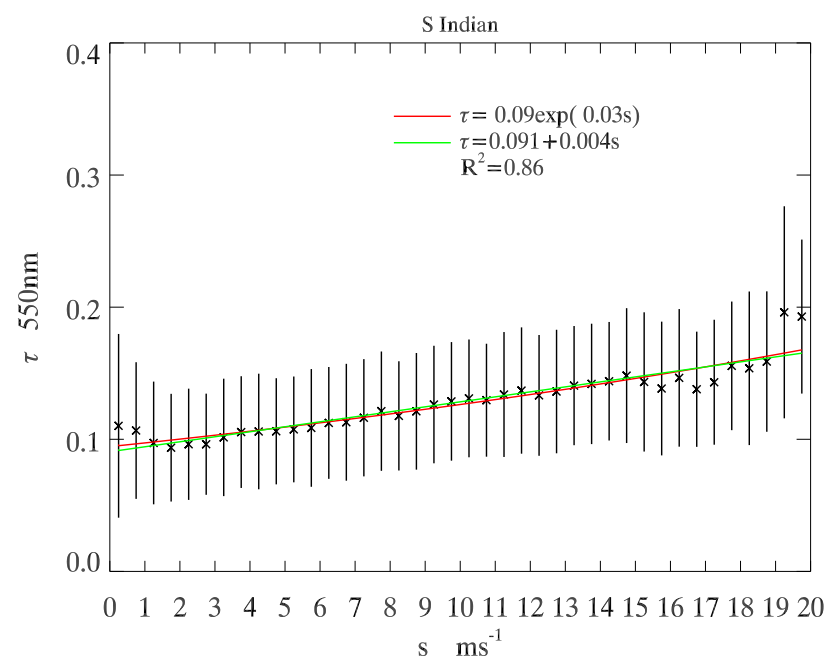

Fig. 8. Relationship between wind speed $s$ and AOD $\tau$ over the South Indian Ocean region.

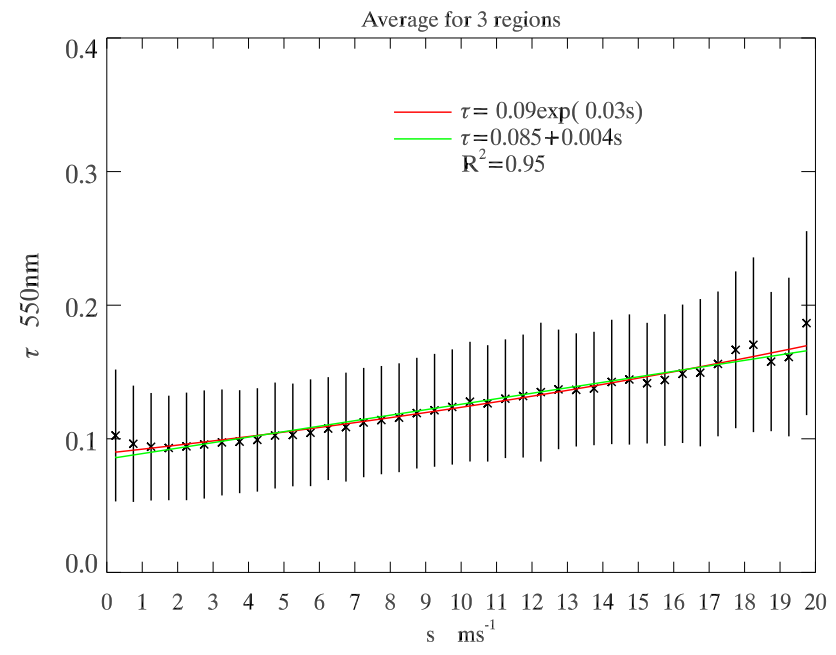

Fig. 9. Relationship between wind speed $s$ and AOD $\tau$ over the three regions.

than a straight line. A linear (green line) and an exponential curve (red line) are fitted to the data. Fig. 9 shows the averaged relationship among the three regions. The linear fit to these data (green line) yields the equation:

$\tau=(0.0850 \pm 0.0002)+(0.0040 \pm 0.0002) \times s$

This result is different from (Mulcahy et al., 2008) and (Glantz et al., 2009), which are taken from the northern Pacific and northern Atlantic respectively, but is very similar to the results of (Smirnov et al., 2003) and (Jennings et al., 2003), which were taken from Midway Island and Tahiti, which are largely thought to be remote ocean areas due to 
their long distances from the mainland. The same analysis has also been performed on the data from 2003 and was in agreement with the 2004 results presented here.

\section{Discussion}

We interpret the enhanced AOD at higher wind speed as a consequence of heavy marine aerosol production introduced by wind. The size distribution of sea salt moves towards the coarse mode as the wind speed increases. Such increase in the number of large particles would result in an increased extinction efficiency at longer wavelengths. Thus, theoretically, one might expect the relationship between wind speed and AOD to be stronger a longer wavelengths.

We have examined the relationship between wind speed and the AOD at $0.87 \mu \mathrm{m}$. The results obtained are similar to the results for the $0.55 \mu \mathrm{m}$ channel presented in the paper. It is difficult to explain why the GlobAEROSOL results do not show a stronger AOD dependence with wind speed at higher wavelengths. Possible explanations include deficiencies in the assumed properties (refractive index and size distribution) of the OPAC aerosol class used in the retrieval or that the increase in average particle size with increasing wind speed is not significant enough to be apparent in these results.

It should be noted that the values of AOD low wind speeds shown in this paper are somewhat larger than have been found for marine by other authors (Mulcahy et al., 2008; Glantz et al., 2009).

In order to test the AOD at low wind speeds, we calculate the clean marine AOD at different wind speeds theoretically. The model used is the OPAC (Optical Properties of Aerosols and Clouds) software package. In the marine boundary layer, the aerosol optical properties is dependent on the number concentration(NC), size distribution of the particles and ambient relative humidity $(\mathrm{RH})$. According to Lewis and Schwartz (2004), the typical RH of the ocean is around $80 \%$, and ECMWF RH data are consistent with this. In OPAC, marine clean aerosol is composed of three compositions: water soluble sulfate, fine mode sea salt, and rare coarse mode sea salt with a default number concentrations of $1500,20,0.023 \mathrm{~cm}^{3}$ respectively. The size distribution of each composition is assumed to follow a log normal distribution. The aerosol optical properties (including AOD) are calculated by Mie theory. The source function of production used here is the well-accepted exponential function : $N=N_{0} \exp \left(a_{0} U_{10}\right)$, where the $N$ is the number concentration of particles and $N_{0}$ is the number concentration of particles at $0 \mathrm{~ms}^{-1}$ wind speed, the value of it decides the offset of the source function, while $a_{0}$ is the slope parameter with a range of $0.02-0.39$, the value found in southern oceans is from 0.031 to 0.049 with an average of 0.037 (Bigga et al., $1995)$, the $U_{10}$ is the $10 \mathrm{~m}$ wind speed.

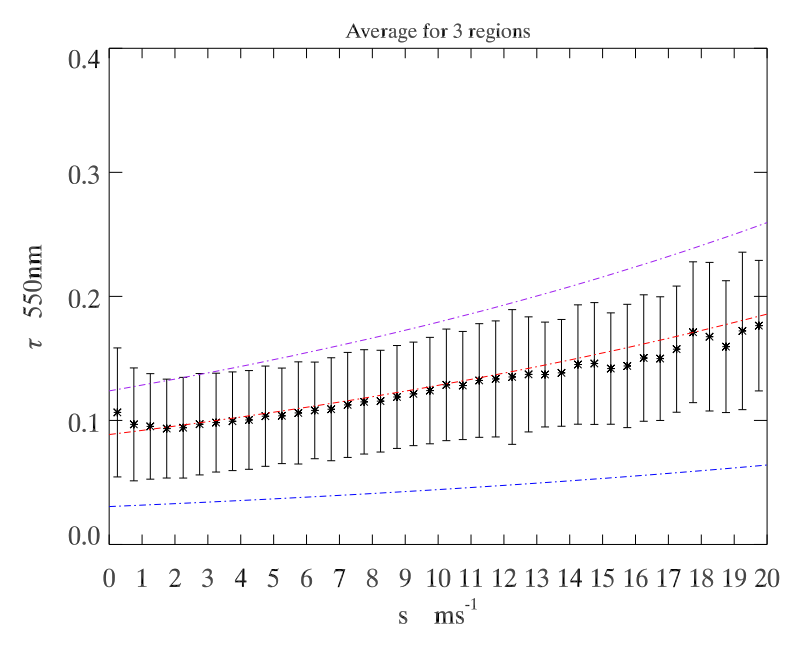

Fig. 10. The relationship between wind speed $s$ and AOD $\tau$ at RH $80 \%$, the black crosses are the averaged result for three regions as shown in Fig. 9, the three dash lines are the OPAC modelled result using different values of $N_{0}$ of sea salt, purple: $30 \mathrm{~cm}^{-3}$, close to the upper limit of sea salt number concentration; red: $20 \mathrm{~cm}^{-3}$, the default value of sea salt number concentration given OPAC; blue: $3.5 \mathrm{~cm}^{-3}$, closed to the lower limit of sea salt number concentration.

Using the default clean marine aerosol parameters given by OPAC and three values of $N_{0}$, the relationship of AOD and wind speed under the RH of $80 \%$ is modelled (Fig. 10). The modelled and observation results have the similar slopes but different offsets, which are sensitive to the value of $N_{0}$. Though the aerosol properties from OPAC are generalized and contain many assumptions, it confirms that the slope of our result is not effected by the systematic error discussed in the Sect. 2.

\section{Conclusions}

In this study, we examine the oceanic AOD at $0.55 \mu \mathrm{m}$ obtained from AATSR as a function of the $10 \mathrm{~m}$ wind fields from the ECMWF. The remote ocean region is defined by its wind direction and AOD. Using this criteria, the majority of the oceans cannot be considered as pristine remote ocean, because of long-range transportation from continents.

A linear relationship with a high correlation coefficient is found between wind speed and AOD at $0.55 \mu \mathrm{m}$ in clear marine environments. The slope of the relationship is unequivocally determined but the offset is probably influenced by a systematic high bias in AOD believed to exist in the GlobAEROSOL product.

Acknowledgements. Haiyan Huang acknowledges the support of a K. C. Wong award. This work was supported by the Natural Environment Research Council [grant number NE/E011187/1].

Edited by: J. Thornton 


\section{References}

Andreas, E. L.: A new sea spray generation function for wind speeds up to $32 \mathrm{~ms}^{-1}$, J. Phys. Oceanogr., 28, 2175-2184, 1998.

Baran, A. J.: A reviewofthelightscatteringpropertiesofcirrus, J. Quant. Spectrosc. Rad. Transfer, 110, 1239-1260, 2009.

Bigga, E. K., Gras, J. L., and Mossop, D. J. C.: Wind-produced submicron particles in the marine atmosphere, Atmos. Res., 36, 55-68, 1995.

Clarke, A., Kapustin, V., Howell, S., and Moore, K.: Sea-salt size distributions from breaking waves: Implications for marine aerosol production and optical extinction measurements during SEAS, J. Atmos. Ocean. Technol., 20, 1362-1374, 2003.

Exton, H. J., Latham, J., Park, P. M., Perry, S. J., Smith, M. H., and Allan, R. R.: The production and dispersion of marine aerosol, Quart. J. Roy. Meteorol. Soc., 111, 817-837, 1985.

Fitzgerald, J. W.: Marine aerosols: a review, Atmos. Environ., 25A, 533-546, 1991.

Ghan, S. J., Guzman, G., and Abdul-Razzak, H.: Competition between sea salt and sulfate particles as cloud condensation, J. Atmos. Sci., 55, 3340-3347, 1998.

Glantz, P., Nilsson, E. N., and Hoyningen-Huene, W.: Estimating a relationship between aerosol optical thickness and surface wind speed over the ocean, Atmos. Res., 92, 58-68, 2009.

Gras, J. L. and Ayers, G. P.: Marine aerosol at southern midlatitudes, J. Geophys. Re., 88, 10661-10666, 1983.

Hegg, D. A.: Modelling the effects of heterogeneous cloud chemistry on the marine particle size distribution, J. Geophys. Res., 97, 12927-12933, 1992.

Heintzenberg, J., Covent, D. C., and Dongenen, R. V.: Size distribution and chemical composition of marine aerosols: a compilation and review, Tellus B Chem. Phys. Meteorol., 52, 1104-1122, 2003.

Hess, M. and Schult, I.: Optical properties of aerosols and clouds: The software package OPAC, B. Am. Meteorol. Soc., 79, 831844, 1998.

Hoppel, W. A., Fitzgerald, J. W., and Mack, E. J.: Aerosol size distributions and optical properties found in the marine boundary layer over the Atlantic Ocean, J. Geophys. Res.., 95, 3659-3686, 1990.

Jennings, S. G., Kleefeld, C., O’Dowd, C. D., Junker, C., Spain, T. G., O’Brien, P., Roddy, A. F., and O'Connor, T. C.: Mace Head Atmospheric Research Station - Characterization of aerosol radiative parameters, Boreal Environ.t Res., 8, 303-314, 2003.

Latham, J. and Smith, M. H.: Effect on global warming of winddependent aerosol generation at the ocean surface, Nature, 347, 372-373, 1990.

Lewis, E. R. and Schwartz, S. E.: Sea Salt Aerosol Production: Mechanisms, Methods, Measurements, and Models, American Geophysical Union, 2004.

Lohmann, U. and Feichter, J.: Global indirect aerosol effects: a review, Atmos. Chem. Phys., 5, 715-737, doi:10.5194/acp-5-7152005, 2005.

McDonald, R. L., Unni, C. K., and Duce, R. A.: Estimation of atmospheric sea salt dry deposition: Wind speed and particle size dependence, J. Geophys. Res., 87(C2), 1246-1250, 1982.

Mishchenko, M. I. and Geogdzhayev, I. V.: Satellite remote sensing reveals regional tropospheric aerosol trends, Opt. Exp., 15, 7423-438, 2007.

Moorthy, K. K. and Satheesh, S. K.: Characteristics of aerosols over a remote island, Minicoy in the Arabian Sea: Optical properties and retrieved size characteristics, Q. J. Roy. Meteorol. Soc., 126, 81-109, 2000.

Moorthy, K. K., Satheesh, S. K., and Murthy, B. V. K.: Investigations of marine aerosols over the tropical Indian Ocean, J. Geophys. Res., 102, 827-842, 1997.

Mulcahy, J. P., O’Dowd, C. D., and Ceburnis, S. G. J. D.: Significant enhancement of aerosol optical depth in marine air under high wind conditions, Geophys. Res. Lett., 35, L16810-L16813, 2008.

Nilsson, E. D., Rannik, U., and Norman, M.: Turbulent aerosol fluxes over the Arctic Ocean 2. Wind-driven sources from the sea, J. Geophys. Res., 106, 32139-32154, 2001.

O’Dowd, C. D. and de Leeuw, G.: Marine aerosol production: a review of the current knowledge, Phil. Trans. R. Soc, 365, 17531774, 2007.

O'Dowd, C. D. and Smith, M. H.: Physicochemical properties of aerosols over the northeast Atlantic: Evidence for wind-speedrelated submicron sea-salt production, J. Geophys. Res., 98, 1137-1149, 1993.

O’Dowd, C. D., Smith, M. H., Consterdine, I. E., and Lowe, J. A.: Marine aerosol, sea-salt, and the marine sulphur cycle: a short review, Atmos. Environ., 10, 1352-2310, 2001.

Platt, C. M. R. and Patterson, G. R.: The interpretation of baseline atmospheric turbidity measurements at Cape Grim, Tasmania, J. Atmos. Chem., 4, 187-197, 1986.

Portela, O., Thomas, G., Poulsen, C., and Grainger, D.: Globaerosol final report, ESA Tech Rep., available online at: http://www. globaerosol.info/docs/globaer_frep_v1p0.pdf, 2009.

Sanderson, M. G.: Emission of carbon monoxide by vegetation and soils, Tech. rep., Hadley Centre, Metoffice, 2002.

Satheesh, S. K. and Srinivasan, J.: Contribution of sea-salt to aerosol optical depth over the Arabian Sea derived from MODIS observations, Geospat. Res. Lett., 33, L03809-L03813, 2006.

Satheesha, S. K. and Moorthy, K. K.: Radiative effects of natural aerosols: A review, Atmos. Environ., 39, 2089-2110, 2005.

Sayer, A. M., Thomas, G. E., and Grainger, R. G.: A sea surface reflectance model suitable for use in (A)ATSR aerosol retrieval algorithms, Atmos. Meas. Tech. Discuss., 3, 1023-1098, 2010, http://www.atmos-meas-tech-discuss.net/3/1023/2010/.

Singer, S. F.: The changing global environment, D. Reidel Publ. Co., Dordrecht-Holland Boston-USA, 1975.

Smirnov, A., Villevalde, Y., O’Neill, N. T., Royer, A., and Tarussov, A.: Aerosol optical depth over the oceans: Analysis in terms of synoptic air mass types, J. Geophys. Res., 16, 639-650, 1995.

Smirnov, A., Holben, B. N., Dubovik, O., Frouin, R., Eck, T. F., and Slutsker, I.: Maritime component in aerosol optical models derived from Aerosol Robotic Network data, J. Geophys. Res., 108(D1), 4033-4044, 2003.

Thomas, G. E., Carboni, E., Poulsen, C., Siddans, R., Grainger, D., Kerridge, B., and Gomez, C.: GlobAerosol: A 12 year global aerosol dataset from European satellite instruments, 2nd MERIS/(A)ATSR User Workshop, 2008.

Thomas, G. E., Carboni, E., Sayer, A. M., Poulsen, C. A., Siddans, R., and Grainger, R. G.: Oxford-RAL Aerosol and flaiCloud (ORAC): Aerosol retrievals from satellite radiometers, in: Aerosol remote sensing over land, edited by: Kokhanovsky, A. A. and de Leeuw, G., Springer, Berlin, Germany, chap. 7, 2009a. 
Thomas, G. E., Poulsen, C. A., Sayer, A. M., Marsh, S. H., Dean, S. M., Carboni, E., Siddans, R., Grainger, R. G., and Lawrence, B. N.: The GRAPE aerosol retrieval algorithm, Atmos. Meas. Tech., 2, 679-701, doi:10.5194/amt-2-679-2009, 2009 b.

Thomas, G. E., Poulsen, C. A., Siddans, R., Sayer, A. M., Carboni, E., Marsh, S. H., Dean, S. M., Grainger, R. G., and Lawrence, B. N.: Validation of the GRAPE single view aerosol retrieval for ATSR-2 and insights into the long term global AOD trend over the ocean, Atmos. Chem. Phys., 10, 4849-4866, doi:10.5194/acp-10-4849-2010, 2010.
Villevalde, Y. V., Smirnov, A. V., O’Neill, N. T., Smyshlyaev, S. P., and Yakovlev, V. V.: Measurement of aerosol optical depth in the Pacific Ocean and the North Atlantic, J. Geophys. Res., 99, 983-988, 1994.

Zavody, A. M., Mutlow, C. T., and Liewellyn-Jones, D. T.: Cloud clearing over the ccean in the processing of data from the AlongTrack Scanning Radiometer (ATSR), J. Atmos. Ocean. Tech., 17, 595-615, 2000. 